\title{
Capecitabine Rapidly Disintegrating Tablet
}

National Cancer Institute

\section{Source}

National Cancer Institute. Capecitabine Rapidly Disintegrating Tablet. NCI Thesaurus.

Code $C 99629$.

A rapidly disinteg rating film-coated tablet composed of the fluoropyrimidine carbamate antimetabolite capecitabine with antineoplastic activity. As a prodrug, capecitabine is converted to 5'-deoxy-5-fluorocytidine (5'-DFCR) by hepatic carboxylesterase and then to 5'-deoxy-5-fluorouridine (5'-DFUR) by cytidine deaminase and is eventually activated by thymidine phosphorylase to its cytotoxic moiety, 5-fluorouracil (5-FU); subsequently, 5-FU is metabolized to two active metabolites, 5-fluoro-2-deoxyuridine monophosphate (FdUMP) and 5-fluorouridine triphosphate (FUTP). FdUMP inhibits DNA synthesis and cell division by reducing normal thymidine triphosphate production, while FUTP inhibits RNA and protein synthesis by competing with uridine triphosphate for incorporation into the RNA strand. Capecitabine rapidly disintegrating tablet (RDT) contains the water insoluble, disinteg rating agent crospovidone which very rapidly disperses and swells in water making this RDT easier to swallow than the traditional capecitabine tablet. 